\title{
The Psychopharmacological Fix: The Suppression of Sadness and the Search for Meaning
}

\author{
Laura Gallo*, BA
}

\section{INTRODUCTION}

As humans, emotions are the most basic resources we have to express ourselves. Feelings are markers of the human condition; they can be our most reliable indicators of pleasure or distress. Over the past few years, we have neglected the fact that feelings, like sadness, are a natural part of life. At some point we have learned that sadness is a forbidden emotion and that melancholia experienced for more than two weeks is cause for serious concern. Certainly, depression can be a grave condition with debilitating effects. While medication is often a requirement for some, it is currently being used as a convenient coping mechanism for others. Why we have turned to the psychopharmacological fix is a question worth examining.

As part of the 2005 Biomedical Seminar Series at McGill University, Joseph Davis Ph.D., a Sociologist from the University of Virginia, gave a talk entitled: "Direct-to-consumer advertising and the anxious self." Twenty-five years ago Social Anxiety Disorder (SAD) was considered to be a very rare condition (1), but today it is the third most commonly diagnosed mental disorder in North America (1). Davis proposed that such a significant increase in the diagnosis of this disorder is linked to the upsurge in the advertisement of prescription drugs like Paxil and Zoloft. Since 1997, when the FDA loosened its restrictions on advertisements of such medication, we have been bombarded with ads promising personal transformation and brighter days to come (1). In 2001, GlaxoSmithKlein spent \$91 million dollars in direct advertisement to its consumers for Paxil, whose campaign insists

\footnotetext{
* To whom correspondence should be addressed: Laura Gallo, Address: 860 54th Ave, Lachine, QC, H8T-3A6, Phone: (514)-6342370, E-mail: lgallo3@po-box.mcgill.ca
}

shyness, anxiety and sadness are debilitating problems that threaten to hold us back from living full lives (2). After all, time is precious in our fast-paced society and we don't have a moment to spare on introspection. But who doesn't feel sad or anxious sometimes? Will popping a pill for every dilemma really make us more capable of living more meaningful lives? The progress of science and the growth of research have allowed the pharmaceutical business to flourish. From the common cold to heartburn to the wintertime blues, there is something available for every discomfort that plagues the North American consumer. The aches and pains that were once simply a part of life are now seen as symptoms to be treated. There is no denying that modern medicine has accomplished many wonderful things, but let there be no doubt that it has also brought with it some potentially harmful side effects. There is no perfect fix and the advent of the anti-depressant era has already raised some important ethical concerns.

One particularly disturbing issue is the fact that pharmaceutical companies profit by marketing to a generally healthy population (1). Ads market antidepressants to a very widespread audience by stigmatizing feelings like sadness and anxiety- feelings almost all of us can relate to. We are made to believe that the images of shiny happy people in these commercials are the way we are supposed to be. Advertisements also encourage self-diagnosis while creating a responsibility to act so that happiness is not only a right, but also a duty (3). Canadians have certainly taken this to heart, as Effexor, Paxil and Celexa were prominent on the top twenty most prescribed medications list for the year 2003 (1). The ease at which these drugs are dispensed is due in part to the de-stigmatization of mental illness (1). Disorders like depression are no longer connected to moral failure because advertisements have shown us that depression 
is purely biological, summing it up to a slight chemical imbalance in the brain (1). But can such a serious problem really be that simple? Probably not. Some argue that the supposed biological causes of depression have never even been proven scientifically. Allen J. Frances, professor of psychiatry at Duke University Medical Center, refutes the claim that depression is even a brain disease at all (4). Unlike most bodily diseases, which can often be detected through concrete means, such as, blood tests and biopsies, there is no such test for mental illness. This fact alone provides insight into another reason why anti-depressants might be doled out so easily: a personal testimony to feelings of sadness could suffice (1). Of course, not all doctors will dispense anti-depressants without evidence of significant distress AND dysfunction. in 1 or more areas of life. Nonetheless, millions of dollars are spent in advertising and gifts to convince doctors to prescribe these medications (5). Even if there is an association between low levels of serotonin and depression it does not necessarily imply that this is the cause of depression. It may also be an effect of mental illness. If this is the case, would it not make more sense to treat the underlying cause, rather than placating the symptoms?

Carl Elliott, a prominent bioethicist at the University of Minnesota Medical School and former professor at McGill University, attempts to address the cause itself. He believes the problem lies in cultural alienation (6). $\mathrm{He}$ writes in his article Pursued by Happiness and Beaten Senseless, "Part of the nagging worry about Prozac and its ilk is that the ills they treat are part and parcel of the lonely, forgetful, unbearably sad place where we live" (6). Rather than placing the blame solely on seretonin, Elliott believes that prevalent sadness is a symptom of the unnatural, isolated, and unhealthy society in which we live. Indeed, these are sad times when the general public embraces a. Perhaps the predicament we are faced with is not something that can be fixed with a trip to the pharmacy, as antidepressants are not the cure-all that their producers make them out to be. Some of our sadness is rooted in the way we live. With modernity and rapidly changing technology, we are drowning in excess: too many choices and too many changes too quickly, overwork and overstimulation (5). We are constantly overwhelmed. Prevalent anxiety and insecurities are more indicative of cultural alienation than of our individual psyches. Unfortunately, medications are geared towards changing our minds not our lifestyleswhich brings us to another ethical concern.

The suppression of sadness, insecurities and anxieties will undoubtedly affect our sense of self, if the way we think and the way we feel are basic constituents of our character. Peter Kramer M.D., the author of one of the last decade's best sellers, Listening to Prozac, cites cases of mildly depressed patients who after taking Prozac underwent remarkable personality transformations (7). People were not just feeling better while on the drug, but better than well. This is somewhat disconcerting. Is Prozac masking the person's true self with a blanket of serotonin, or is it uncovering the self that was hidden in anxiety? SSRI's (selective serotonin reuptake inhibitors) change the functioning of the brain so that the authentic self is altered, perhaps unrecognizably (5). According to Kirmayer, antidepressants alter the self in three ways: "(i) it changes the bodily feeling and stance that subserve our metaphorical constructions of the self, for example, by making us feel more uptight and energized; (ii) it provides a new inner agent to which to attribute our feelings... and (iii) it may reshape our empathic response to others" (5).

The question of the authentic self spawns several dilemmas. First, in a society that values individuality, what will become of our uniqueness if we all conform to car-salesmen personalities? One of the reasons that people become depressed in the first place is because they feel their lives are not unique (3). Have we come full circle? Secondly, a drug that alters mood changes the emotional reactivity to persons and events, therefore reshaping one's sense of self (5). Again, this is contradictory to popular belief that says that an inauthentic life is a failed life (3). How can a life be made meaningful through inauthentic means? It is a Catch-22.

Perhaps part of the problem is that leading a fulfilling life is so completely dependent upon a person's internal state (3). With the decline of religious adherence (especially here in Quebec) (8), the weakening of social support networks (3) and the burden of the workweek, people are lacking anything of value beyond the self (3) . If all that matters is self-fulfillment then occasionallynormal feelings such as unfulfillment or unhappiness can become socially unacceptable. Dissatisfaction with life implies failure and because failure is not an ideal to which anyone aspires, it should be changed. As the slogan for Paxil goes, "your life is waiting." (1).

But in "getting our lives back", what exactly are we reclaiming? A life free of pain and suffering? A life sheltered from the dissatisfaction and distress with the social world? Rather than teaching ourselves how to avoid suffering, perhaps we need to learn how to suffer, even if it is socially unacceptable. Rather than dulling our senses when they tell us something we don't want to hear, it is time to listen to them, for they are our most reliable assets. 


\section{REFERENCE:}

1. Davis, Joseph. "Getting Your Life Back: Direct-to-Consumer Advertising and the Anxious Self." 2005 Bioethics Seminar Series. City of Montreal. Biomedical Ethics Unit, McGill University, Faculty of Medicine; 27 Jan. 2005.

2. Chatterjee, Anjan. "Cosmetic Neurology: The controversy over enhancing movement, mentation, and mood." In Neurology 63:968-974; 2004.

3. Elliott, Carl. "The Tyranny of Happiness: Ethics and Cosmetic Pharmacology." In Enhancing Human Traits: Ethical and Social Implications. Ed. Erik Parens. Washington, D.C.: Georgetown University Press, 177-188; 1998.

4. Wikipedia: the Free Encyclopedia. 7 Feb 2005. http://en.wikipedia.org/wiki/Selective_serotonin_reuptake_inhi bitor
5. Kirmayer, Laurence. "Psychopharmacology in a Globalizing World: The use of Antidepressants in Japan." In Transcultural Psychiatry 39, 3: 295-322; 2002.

6. Elliott, Carl. "Pursued by Happiness and Beaten Senseless: Prozac and the American dream." In Hastings Center Report 30, 2: 7-12; March-April 2000.

7. Kramer, Peter D. Listening to Prozac. London: Fourth Estate Limited, 1994.

8. Statistics Canada: The Daily May 13th, 2003. retrieved 24 April 2005.

http://www.statcan.ca/Daily/English/030513/d030513a.htm

Laura Gallo recently completed her Bachelor of Arts in World Religions at McGill and will begin her Masters in the History and Philosophy of Religion this fall. Her current areas of interest lies in religion and medicine. She has been writing for Radix, McGill's multifaith publication, and plans to pursue academic writing and professorship in future endeavours. 